\title{
Implement and Innovate Environmental Protection Measures, Promote Green Protection of Cultural Relics in the Three Gorges Area
}

\begin{abstract}
The subject is implementing and innovating environmental protection measures, and promoting green protection of cultural relics in the Three Gorges area. This thesis states its significance and effect in the beginning, and then summarizes seven pieces of main practice, includes five pieces of main effect. In the end, this thesis produces some relevant conclusions and suggestions about the subject.
\end{abstract}

Keywords: environmental science, the Three Gorges cultural relics, innovate environmental protection measures, green protection

\section{Introduction}

The Yangtze Three Gorges area is one of the cradles of Chinese civilization. The protection of cultural relics in the Three Gorges area was carried out as part of the Three Gorges project construction. It is a national culture protection project. The protection is the largest in scale and the widest in protection range, and its number of participants is the largest in our country. Implementing and innovating environmental measures and promoting green protection of cultural relics in the Three Gorges area is the basic national policy to implementing ecological protection of environment. It is the important content of the construction ecology of Three Gorges project. It is to protect the cultural relics of Three Gorges project. Its precondition is to ensure the safety of cultural relics. It is a collection of communal participation of a variety of disciplines. It adopts technical, engineering and ecological methods. It tries to reduce the effect on the environment of

Manuscript received June 1, 2014; accepted September 15, 2014

Fu-qing Liang $(\bowtie)$, Yong-ping Sun

The State Council Three Gorges Project Construction Committee Executive Office, Yichang 443003, China

Email: liang_fuqing@sina.com underground excavation and rehabilitate ground cultural relics. It prevents major pollution and environmental destruction. It attaches great importance to supporting construction of an ecological environment and of sustainable development in cultural relic protection. Its ultimate objective is to realize harmonious and sustainable development among natural environment and human and economic environment in the cause of cultural relic protection.

Between 1993 and 2010 in the past 18 years, our Party and State attached great importance to promoting green protection of cultural relics in the Three Gorges area. Our State and governments at all levels in the reservoir area, departments of cultural relic protection, other relevant departments were highly responsive to our country and the Chinese people. They earnestly implemented and innovated environmental measures. They earnestly promoted green protection of cultural relics in the Three Gorges area. The task of protecting 1,087 cultural relics in the Three Gorges reservoir area has been all completed successfully and on schedule. There were 364 ground projects and 723 underground projects. The archeological excavation covered $1.72 \times 10^{7} \mathrm{~m}^{2}$. The stationary capital for cultural relic protection was $5.0587 \times 10^{8} \mathrm{CNY}$ at last (Ling, 2009). The protection of four key projects and ground cultural relics has been completed on schedule with high quality. The four key projects are: (1) White Crane Ridge Hydrometric Lithoglyph in Fuling; (2) Zhangfei Temple in Yunyang; (3) Shibao Stockade in Zhong County; (4) Quyuan Temple in Zigui. The ground cultural relics include: (1) Double Palace of Han Dynasty in Zhong County; (2) Ancient Dwellings of Dachang Ancient Town in Wushan; (3) Lithoglyph on Qutang Gorge Wall in Fengjie; (4) Breeze Pavilion in Badong; (5) Dwellings of Green Beach in Zigui and others. A large number of historical and cultural heritage sites and monuments have been properly protected. This has created the material conditions for tourism development in the reservoir area. These heritage sites and monuments cover ancient architecture, cliff figures rock, 
stele, poetic inscription, flood hydrologic inscription, ancient plank road and others, which have the traditional style of the Three Gorges area. During underground archeology in the reservoir area, more than 240,000 cultural relics were been unearthed, of which over 60,000 pieces were considered precious. A complete sequence of the Three Gorges culture and history has been preliminarily constructed, which collects a large amount of material data for studying the cultural development, civilization process, environmental change, and the evolution of social conditions in the Three Gorges area. The investment of cultural relics protection was controlled within the scopes of contracts. The measures for implementing and innovating environmental protection were fundamental. There were no major quality accidents or environmental safety problems concerning the protection of cultural relics. The protection of cultural relics has achieved remarkable green benefit. Consequently the cultural relic protection in the Three Gorges area became a model that the protection of cultural relics practiced Scientific Concept on Development in our country.

\section{Main practices}

2.1 Established and perfected management system suiting for China's national conditions in time

Our country established and perfected a protection and management mechanism for cultural relics in the Three Gorges area early in the process. The State Council Three Gorges Project Construction Committee led throughout the process. Several departments were charged with the work of protecting cultural relics. This group consisted of the State Council Three Gorges Construction Committee Executive Office, the State Council Three Gorges Construction Committee Emigrant Development Bureau, the State Administration of Cultural Heritage, Hubei Provincial Government and its Cultural Relics Administrative Department, Chongqing City Government and its Cultural Relics Administrative Department, numerous district and county governments, and numerous cultural relics administrative departments in the reservoir area. These departments divided the work and planned it as a whole. Each department implemented a uniform responsibility system for the cultural relic protection. They organized to improve and supervise to implement relevant environmental measures of cultural relics. This management mechanism suited China's national conditions and the need for green protection of cultural relics in the Three Gorges area. It played an important role in implementing earnestly and innovating environmental measures, also in improving green protection of cultural relics in the Three Gorges area (Xu, 2006).
2.2 Worked out environmental impact report and cultural relic protection planning of the Three Gorges on time

In 1993, state environmental departments organized people to compile The Environmental Impact Report for the Yangtze Three Gorges Water Conservancy. Environmental protection standards for cultural relic protection projects in the reservoir area were produced in the report. Four key cultural relic protection projects were among them: (1) White Crane Ridge in Fuling; (2) Shibao Stockade in Zhong County; (3) Zhangfei Temple in Yunyang; (4) Quyuan Temple in Zigui. The report guided environmental measures to be implemented in order and innovated in the work of cultural relic protection in the Three Gorges project. This ensured that the cultural relic protection in the Three Gorges project was effected in an environment within controllable range (The former State Environmental Protection Administration, 1992).

In 1998, State Administration of Cultural Heritage organized people to compile The Planning Report of Protection of the Cultural Relics in the Submerged and Relocation Areas of Yangtze Three Gorges Project, which created the first planning of its kind so that planning can go ahead of implementing in the protection of cultural relics in China, also established a new order that was suitable for the great protection project of cultural relics. At the same time, the protection planning of cultural relics in the Three Gorges area also produced corresponding requirements to the environmental measures of implementing the protection of cultural relics (State Council Three Gorges Project Construction Committee Executive Office, 2010).

2.3 Management measures and specifications for cultural relic protection in the Three Gorges reservoir area

After 2000, Chongqing City and Hubei Province issued management measures for protecting cultural relics in the Three Gorges reservoir area. The relevant district and county governments and cultural relic protection units also formulated, issued and implemented measures and detailed rules to guide the cultural relic to assure that the work went smoothly. Environmental protection was implemented concretely also in protecting cultural relics.

In 2008, State Administration of Cultural Heritage issued formal work rules and relevant implementing provisions for field archeology. Underground archeological excavation plans were required to include plans for cultural relic protection, disaster prevention plans, and the safety and content of protecting ecologic environment planning. Principles and rules for maintaining and managing the environment, cleaning the environment and protecting the ecologic environment, such as disposing wastes, disinfecting hazardous substances and treating life wastes in the archeological sites, e.g. cleaning in the sites, filling and restoration, restoration of farming, restoration of vegeta- 
tion, were required. At the same time, cultural relic management departments in the reservoir area often checked and supervised archeological excavation units to enforce strictly the archeological regulations in the field. This pushed forward the concrete implementation of site management and environmental measures in the excavation of underground cultural relics.

2.4 Established and perfected advanced management mechanism and approach

During the implementation of the cultural relic protection plan in the Three Gorges area in the past 18 years, we have referred to and introduced advanced management mechanisms and approaches from domestic and foreign engineering construction and other industries which included project legal personnel system, project contract system, engineering invitation and bid systems, engineering supervision system, lifelong quality responsibility systems, acceptance after completion, financial audits and others. Especially, one of the referred above was a comprehensive supervision system of monitoring and evaluation system from the World Bank. This marked a management level including environmental protection of protecting cultural relics in the Three Gorges area that reached a leading level in the field of protecting cultural relics for our country. At the same time, the projects of protecting cultural relics strengthened the management of construction sites. They achieved hard to civilized construction. The sewage, waste soil, solid waste, dust, garbage, harmful gas, noise, etc. produced from construction have been handled properly. The internal and external environments of construction sites have been protected well, which avoided environmental pollution and soil erosion. Furthermore, the environmental inspection was strengthened while accepting the projects of protecting cultural relics after completion. The environmental measures were ensured to be put in place (Liang, 2009).

\subsection{Multidisciplinarity, applied technology and environmental materials}

Efficiency and quality improved because many disciplines were involved in protecting cultural relics in the Three Gorges area. These disciplines cooperated. They included archeology, architecture, ethnology, culturology, underwater archeology, aerial archeology, geological prospecting, geographical mapping, life sciences, modern medicine, environmental protection, ecological civilization and others. Technical, engineering and ecological methods were synthesized. The environmental protection measures were implemented seriously and innovated upon. Green protection for cultural relics in the Three Gorges area was promoted by them. High technology, scientific methods, and environmental materials were introduced and adopted. This included physical exploration, electronic mapping, proton-induced X-ray techniques, DNA (DNA) techniques, stratum extraction techniques, remote sensing archeology, environment mapping, topography detection, carbon-14 dating methods, atomic absorption spectroscopy, atomic emission spectroscopy, X-ray fluorescence spectrometry, infrared photography, sporopollen analysis, campestral archeological software, information technology, nanomaterials and others. The efficiency and quality of protecting cultural relics were improved. Environment impacts from protecting cultural relics were reduced. New materials, techniques and processes which were green and environmental were used to restore ground cultural relics which improved environmental quality and benefitted from protecting cultural relics (Hao, 2006).

\subsection{The environmental evaluation system and environmental measures implemented to protect large cultural relics}

When the protection scheme for the ground cultural relics was formulated in the reservoir area, the environmental evaluation was carried out synchronously. Cultural relic protection and environmental protection were integrated. Synchronous planning, synchronous design and synchronous implementation were realized. Environmental harm that an engineering project might cause was predicted and evaluated beforehand. It was made clear that environmental protection was an important condition for evaluating engineering quality for cultural relic protection. Excellent systems and mechanisms were used so that the environmental measures were implemented during cultural relic protection projects. Environmental measures were established and implemented in the protection projects of large area cultural relics especially in the centralized rehabilitation areas for ground cultural relics in the reservoir area. This included biologic reforestation, sewage treatment, solid waste disposal and waste recycling. These measures were normalized. The influence on the environment was significantly reduced. Among them, there were the four key cultural relic protection projects: White Crane Ridge in Fuling, Shibao Stockade in Zhong County, Zhangfei Temple in Yunyang, and Quyuan Temple in Zigui. These areas implemented environmental three-synchronization system and relevant environmental measures on the whole. Construction site management was ordered. Inside and outside environments of the construction areas were well protected. Relevant requirements for environmental impacting reports in the Three Gorges were reached. Furthermore, the construction completion acceptance was passed successfully which included environmental protection. Currently the White Crane Ridge in Fuling underwater museum is the first underwater hydrological museum in the world. It is a world leader in engineering and is typical engineering which has practiced fully our country's Scientific Concept on Development. 
2.7 Ground cultural protection projects of adapted to and satisfied new environmental requirements

During the 18-year period of protecting ground cultural relics for the Three Gorges project, the government successively issued higher and more scientific laws and regulations to protect the environment. The standards of controlling environment was improved and continually updated. This was particularly true for controlling standards covering drinking water, sewage, air quality, noise, energy efficiency and emission reduction which improved greatly. Ground cultural relic protection during the Three Gorges project kept pace with the times and implemented environmental measures in accordance with evolving standards. The emphasis focused on the scientific management of construction sites. Many new environmental materials, new technologies and new processes were adopted in energy-saving, emission-reduction, sewage treatment, waste soil processing, re-forestation, fire prevention, pest control, moisture-proofing, noise control and other areas. Not only the quality of implementing environmental measures in the projects of protecting cultural relics was improved, but also the environmental standards in the construction areas were improved. The standards were constantly adapted to and satisfied the requirements of the ecological environment. This created better conditions for the project in protecting cultural relics.

\section{Main results}

3.1 Innovations and enhancing consciousness of environmental cultural relic protection

The policies and principles of cultural relic protection were fully implemented and faithfully enforced to protect cultural relics in the Three Gorges area. Protection was the key. Rescue, rational utilization and strengthening management were primary. The protection principle was to not change the original form of the cultural relics. The people affirmed and widely accepted the concept of ecological civilization for protecting cultural relics which included paying attention to the ecological environmental construction and service facilities supporting construction for cultural relic protection. The peoples' concept of environmental protection was greatly enhanced because cultural relic protection law and environmental protection were widespread and implemented over a long period around the reservoir area. Another reason was that relevant environmental regulations and requirements of environmental evaluation reports were strongly implemented. Implementing and innovating environmental measures and promoting green protection for the Three Gorges cultural relics in the work of protecting cultural relics became a basic consensus and conscious action by the people.
3.2 Ensuring physical and environmental security for cultural relics

The environmental regulations, standards, and requirements of environmental evaluation report were implemented seriously in the protection of cultural relics in the reservoir area. The technical, engineering, and ecological methods were adopted comprehensively. The new technologies, new processes, and new materials of green environmental protection were used hardly to protect cultural relics. The management in construction sites was strengthened to protect cultural relics so as to realize scientific management and civilized construction. Moreover, the geological disaster prevention in the rehabilitation areas of protecting cultural relics was paid attention to. The comprehensive control of soil and ecological environmental supporting construction were also paid attention to. The environmental influence caused by the protection of cultural relics was reduced to controllable range with efforts. The physical security and environmental security of the Three Gorges cultural relics were fully ensured.

3.3 Achieving remarkable environmental protection for cultural relics

During these 18 years we insisted on implementing Three Gorges cultural relic protection using the Scientific Concept of Development everywhere in the reservoir area. We followed ecological economy, social development, and natural laws. We implemented and innovated environmental measures in accordance with the characteristics of cultural relic protection. We fully implemented the requirements of environmental measures that were produced in the report of environmental influence for the Three Gorges project. The environmental effects of protecting cultural relics are notable. The task of protecting Three Gorges project cultural relics has been completed completely on schedule. The investment of protecting cultural relics was controlled within the scope of contracts. There were no major quality accidents or environmental safety problems in cultural relic protection.

3.4 Promoting harmony between cultural relics and the environment while enhancing the value of cultural relics

The environmental laws and regulations, environmental valuation report and planning for the cultural relic protection were vigorously implemented in the reservoir area. Environmental measures were constantly implemented and continually improved. Green protection for Three Gorges cultural relics was constantly promoted. These constantly promoted a harmony between the cultural relic protection and ecological environment appeared. Cultural relics and environment protection developed harmoniously and sustainably so that cultural relic values were promoted significantly. State level units for protecting cultural relics 
in the reservoir area increased to seven, and six of which were new. Provincial or municipal level units of protecting cultural relics increased to 36 , and 20 of which were new.

3.5 Public recognition and satisfaction with innovative and implemented environmental measures to protect Three Gorges cultural relics

Between April to May in 2013, the Resettlement Management Consultation Center of the State Council Three Gorges Project Construction Committee Executive Office went to 11 districts and/or counties in the Three Gorges reservoir area specifically to investigate public opinion concerning environmental protection of cultural relics and landscapes during the construction of Three Gorges project for the period 1993 to 2009. The investigation activities adopted two methods: (1) scene interview; (2) questionnaire survey. There were 118 scene interviews. And 118 questionnaires were given out and recovered. The people surveyed included experts, employees, and resettlement department leaders in the fields of culture, cultural relic, tourism and museum. The people surveyed also included workers, residents, peasants and immigrants from the sites. The survey was concerned with how the Three Gorges project construction affected cultural relics, natural scenes and tourism; whether the people were satisfied with the environmental measures and effects of cultural relics and natural scenes; whether the people were satisfied with tourism development and immigrant employment promoted by the Three Gorges project construction. The survey also included relevant opinions and suggestions. The survey covered the 5 aspects mentioned above. A summary and statistical analysis concluded: $22.78 \%$ of the surveyed people were satisfied with the work of implementing and innovating environmental measures during the cultural relic protection of Three Gorges project; $72.22 \%$ were basically satisfied with the work; $5 \%$ were not satisfied. The results reflected that the public in the reservoir area recognized as a whole and were basically satisfied with the work of implementing and innovating environmental measures of cultural relic protection of the Three Gorges project.

\section{Conclusions and suggestions}

\subsection{Conclusions}

(1) Earnestly implementing and innovating environmental measures to promote green protection of the Three Gorges cultural relics is an important measure to promote sustainable development while protecting the Three Gorges cultural relics.

The orderly carrying out the environmental work for Three Gorges cultural relics, implementing and innovating environmental measures accordingly can ensure that the environmental influences caused by the protection efforts of Three Gorges cultural relics are controllable. It guarantees, in main, social safety and environmental safety for cultural relics. It promotes harmonious development between cultural relics socially and environmentally. It can enhance cultural relic value. It can promote sustainable development while protecting Three Gorges cultural relics. Earnestly implementing innovative environmental measures promotes the green protection of Three Gorges cultural relics as an important measure to effectively improve protection benefits of Three Gorges cultural relics and promote sustainable development while protecting Three Gorges cultural relics.

(2) Much work remains in the further implementation and innovation of environmental measures to promote sustainable development while protecting Three Gorges cultural relics.

By researching Three Gorges cultural relic protection and surveying the public opinion, we realize that there are still some shortcomings and problems in the work of implementing environmental measures of protecting Three Gorges project cultural relics. For example, there is still gap between environmental publicity and education about cultural relic protection and the public's demands. Uniform environmental testing standards are still lacking in the area of archeological excavation of underground cultural relics and the rehabilitation and protection of ground cultural relics. Problems still exist in a few ground cultural relic areas. The problems in the overall environments do not match. The problem of water quality in the case of Fuling White Crane Ridge underwater museum exists due to possible pollution. The Zhangfei Temple in Yunyang has potential geological hazards. These shortcomings and problems need to be addressed as a whole and solved properly in the Three Gorges subsequent work.

\subsection{Suggestions}

(1) We should persist in controlling the work of protecting cultural relics in the subsequent Three Gorges work as a whole using Scientific Concepts of Development. We should implement and innovate environmental measures well. We should promote green protection of cultural relics in any subsequent Three Gorges work. Our ultimate aim is to construct a beautiful Three Gorges reservoir area quickly.

(2) We should strengthen a modern concept of cultural relic protection, and publicize and educate regarding environmental protection for Three Gorges cultural relics and scenery. We should forcefully promote hardly public environmental awareness, consensus and conscious action. We should promote to the implementation and pursue innovate environmental measures with concerted efforts devoted to the work of protecting cultural relics and scenery in any subsequent Three Gorges work.

(3) We should strengthen environmental scientific 
research for the protection of cultural relics and scenery in the subsequent Three Gorges work. We should issue timely specific regulations and testing standards for environmental protection in restoring ground cultural relics, archeological excavation of underground cultural relics and protection of scenery in subsequent Three Gorges work.

(4) We should pay close attention to overall environmental support problem in the restoration areas of Three Gorges ground cultural relics. We should solve the problems of inner and outside layout supporting overall environmental coordination for ancient architecture restoration. At the same time, we should make more efforts to collect exhibits of cultural relics. We should transfer the reuse of cultural relics and enrich the using connotation of cultural relic resource. In addition, we should improve the economic value of tourism for cultural relic resource.

(5) We should vigorously strengthen cultural relic protection, scenery protection and environmental protection in riparian zones and ecological barrier zones around the Three Gorges reservoir. We should improve the quality and benefit of environmental protection.

(6) We should quickly research water quality monitoring and potential pollution problems particularly in the case of the Fuling White Crane Ridge underwater museum in order to prevent water pollution. Our ultimate aim is to ensure that the White Crane Ridge underwater museum operates safely.

(7) We should strength the great ground cultural relics restoration projects, environmental geological surveys in the cultural relics restoration areas, early warning and prevention of geological disasters, such as Zhangfei Temple in Yunyang. This should be done so that we can ensure environmental safety of the great ground cultural relic restoration project and in restoration areas.

\section{References}

Hao, G. (2006). Review the protection of Three Gorges cultural relics. Outlook New Weekly, (21), 60-63

Liang, F. (2009). Review the protection of cultural relics in the Three Gorges reservoir area and subsequent protective countermeasures. Journal of Chongqing Three Gorges University, (6), 1-5

Ling, F. (2009). Protection and development of cultural relics in the Three Gorges Reservoir Area. Chongqing Social Science, (6), 85-88

State Council Three Gorges Project Construction Committee Executive Office. (2010). Planning report of protecting cultural relics in the submerged and relocation areas of Yangtze Three Gorge Project. Beijing: China Three Gorge Publishing House

State Environmental Protection General Bureau. (1992). Environmental impact report of the Yangtze Three Gorges water conservancy project. Beijing: State Environmental Protection General Bureau

$\mathrm{Xu}, \mathrm{G}$. (2006). Achievements and basic experience of the protection of cultural relics in the Three Gorges Project. China Cultural Heritage Scientific Research, (2), 1-5 